\title{
Surgical Research
}

\section{Splenectomy in Special Cases}

\author{
Mihaela Leşe*
}

\begin{tabular}{l|l} 
& *Correspondence: \\
General Surgery Department, Emergency County Hospital of Baia & $\begin{array}{l}\text { Mihaela Leşe, MD, PhD, General Surgery Department, } \\
\text { Eare, 31, G. Coşbuc Street, Baia Mare, Romania. }\end{array}$ \\
$\begin{array}{ll}\text { Baia Mare, Romania. } \\
\text { Received: } 04 \text { April 2019; Accepted: } 25 \text { April } 2019\end{array}$
\end{tabular}

Citation: Mihaela Leşe. Splenectomy in Special Cases. Surg Res. 2019; 1(1): 1-5.

\section{ABSTRACT}

Background: The indications of splenectomy and its ways to perform are today well coded. Recognizing the risks of fulminant infections and discoveries in the field of surgical techniques, in anesthesia but also in hematology and oncology, have reduced morbidity and mortality rate after total or partial splenectomy, regardless of the disease for which it was indicated.

Case Presentation: The article aims to present two cases of splenectomy performed in special conditions: spleen lesion operated laparoscopically in child and splenectomy in case of extreme splenomegaly, with the revision of the specialized literature.

Conclusion: Laparoscopic splenomectomy is feasible in case of splenic trauma, provided that the condition of the patient is stable and a well-trained team and high-performance medical equipment are available. In the case of splenomegaly, the adhesions and the branching of the spleen vessels make the difference between easy and difficult splenectomy.

\section{Keywords}

Laparoscopic splenomectomy, Surgery, Spleen, Bone marrow, Blood cells.

\section{Background}

Laparoscopic splenomectomy is the standard procedure in elective spleen surgery and has few contraindications: spleen traumatic lesions [1] and giant splenomegaly [2]. The management of the spleen trauma has evolved considerably however from exploratory laparatomy with splenectomy, to nonoperative management, partial splenectomy and laparoscopic splenectomy. There is more and more reporting of the minimally invasive approach to spleen trauma and although laparoscopic splenectomy in trauma requires a longer time of surgery [3], patients benefit from all the advantages of this procedure. Splenomegaly was considered the open surgery privilege but with the evolution of surgeons' experience and that of the equipment, the indication of laparoscopic splenectomy expanded to splenomegaly of up to $1000 \mathrm{~g}$ or maximum size of $15 \mathrm{~cm}$ [4]. When the spleen is larger than $19 \mathrm{~cm}$, hand assisted laparoscopic splenectomy is recommended [5]. However, the conversion rate is higher in these cases; therefore, open surgery is preferred [6]. The paper proposes to present splenectomy in two special cases: the laparoscopic approach for traumatic lesions in a child and conventional surgery in a patient with extreme splenomegaly.

\section{Case I}

An 11-year-old boy was brought to hospital after falling from a height of 6 meters, hemodynamically stable, without any notable pathological history or family medical history. In the initial assessment, laboratory tests were only slightly changed relative to normal values for his age: hemoglobin - $12.1 \mathrm{~g} / \mathrm{dl}$, hematocrit - 34.7, white blood cells count - 4,360/ $\mu$ l. CT scan with contrast showed fluid in subhepatic, perisplenic, parietocolic and pelvic compartments (Figure 1), having as a source a spleen rupture in the hilum (Figure 2). There have been no other traumatic injuries to the abdominal or thoracic viscera neither of the bones. Due to the spleen lesion in the hilum, the presence of blood in more than two abdominal compartments and the hemodynamic stability of the child, the surgery was decided to be carried out by the laparoscopic approach.

\section{Surgical setting}

The semi-lateral position that allows fast conversion to open surgery 
was preferred: the patient in dorsal decubitus, with the left body side slightly elevated and the operating table inclined to the right, which made an angle of about $45^{\circ}$ for the left hypochondrium. The operating table was also placed in reverse Trendelenburg. In this way, the spleen was exposed and the abdominal viscera removed from the operator field. The four-trocar technique was used: a 10 $\mathrm{mm}$ trocar for the optics and two working trocars of 5 and one of $10 \mathrm{~mm}$. The pneumoperitoneum was created through umbilical puncture and intraabdominal pressure was set at $12 \mathrm{~mm} \mathrm{Hg}$ and then increased to $14 \mathrm{mmHg}$.

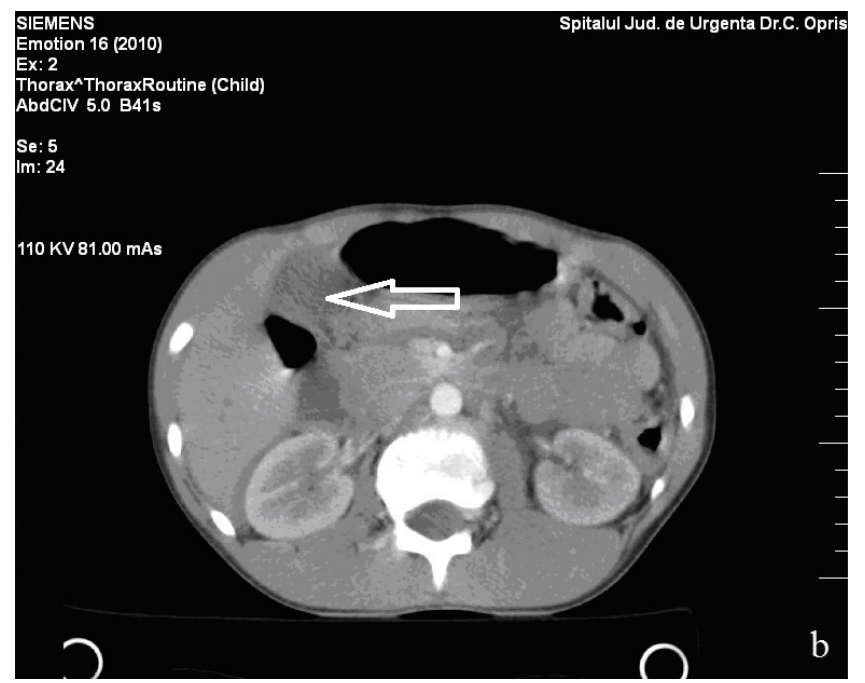

Figure 1: CT with contrast of upper abdomen.

Legend: The white arrow indicates blood in the abdominal cavity.

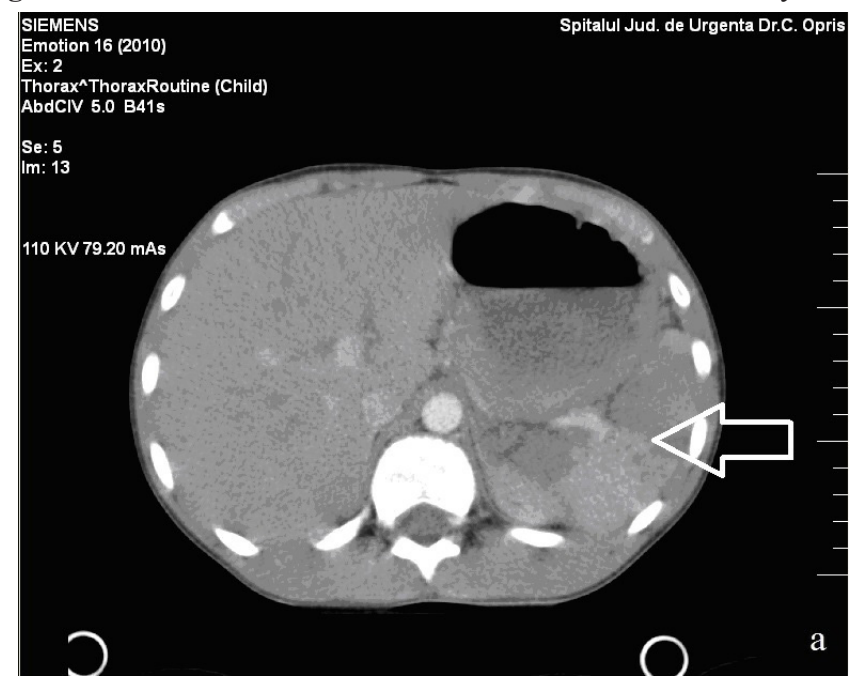

Figure 2: Figure 1. CT with contrast of the spleen.

Legend: The white arrow indicates the splenic artery and the devascularization of the two spleen poles.

\section{Surgical technique}

The examination of the abdomen confirmed the lesions described radiologically, the spleen having two fissures in the hilum, separating the central part of the two poles. No active bleeding was detected and it was decided to continue the surgery by laparoscopy. In elective laparoscopic surgery, we start the operation by splenic artery ligation on the upper edge of the pancreas, but in this case, it was not possible due to the blood infiltration of the pancreatic lodge. Using 5 and $10 \mathrm{~mm}$ LigaSure $\AA$ sealing instruments, the vessels of the lower pole were divided (Figure 3), and then the spleen was disconnected from the stomach (Figure 4). The main hilum vessels remained and were cut with the $10 \mathrm{~mm}$ vascular sealing instrument (Figure 5). After disconnection, the spleen was placed in a sterilized bag for freezer and removed into small pieces through the $10 \mathrm{~mm}$ trocar hole, after it was slightly enlarged with retractors. The blood from the abdomen was removed and two drain tubes were placed in the abdominal cavity. The operation lasted 150 minutes and $400 \mathrm{ml}$ of blood were evacuated from the peritoneum. A short video montage of the operation is available on the internet [7].

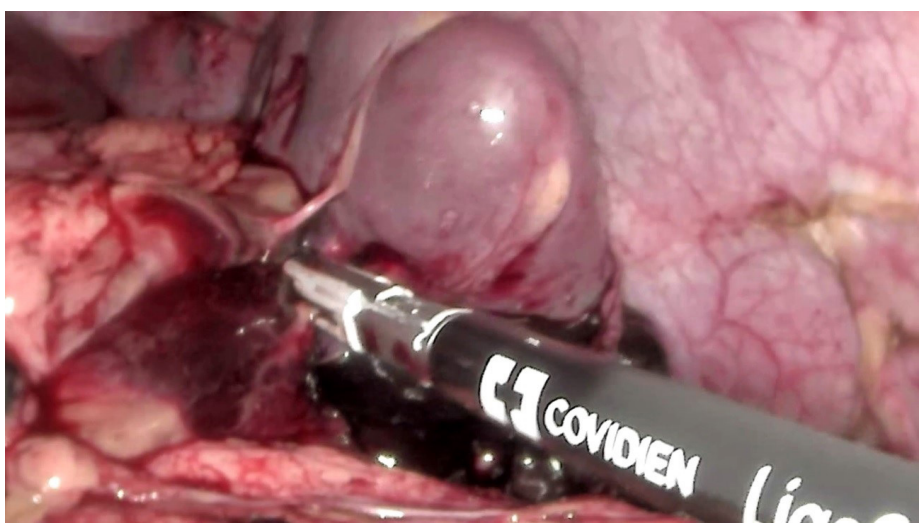

Figure 3: Sealing vessels from the lower pole of the spleen.

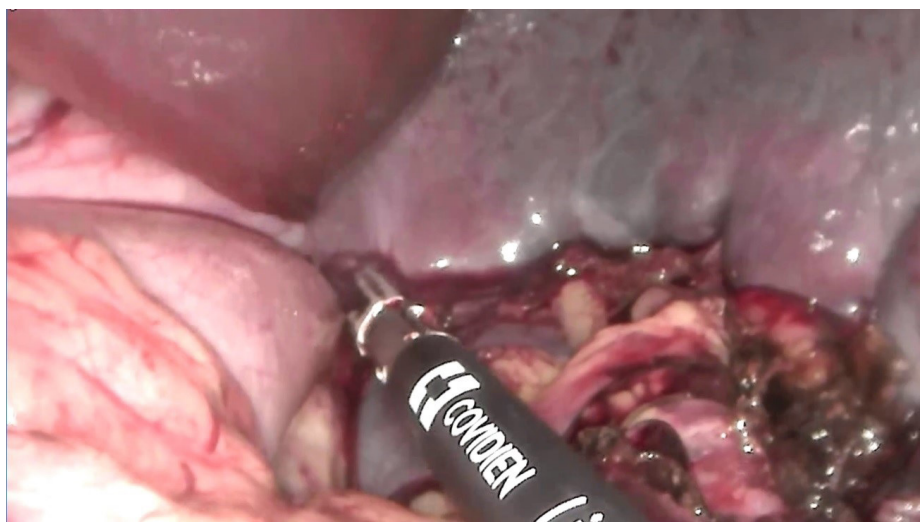

Figure 4: Disconnecting the spleen from the stomach.

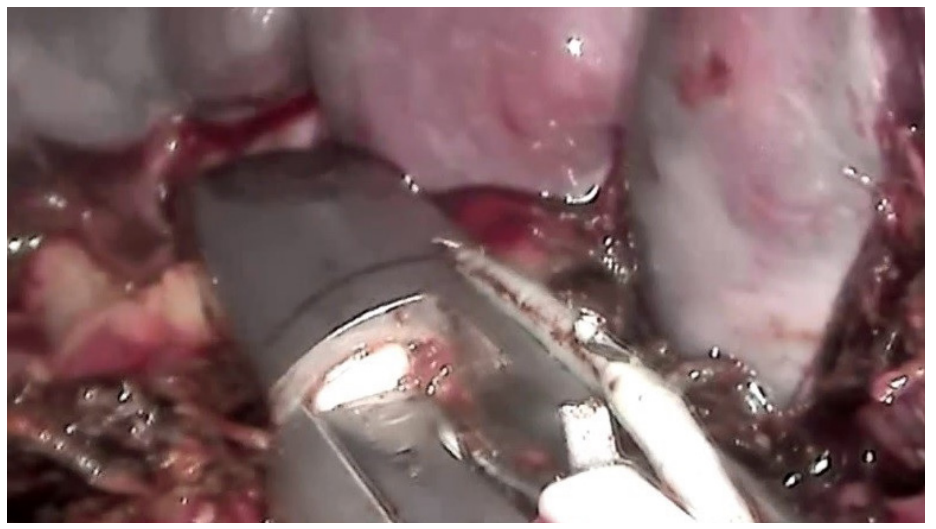

Figure 5: Sealing of the main hilum vessels. 


\section{Postoperative evolution}

The patient was mobile on the first postoperative day, and the intestinal transit was resumed after 48 hours. The drainage tubes were removed on postoperative day 2 and 3. Amoxicillin and clavulanic acid were administered preoperative and 4 days postoperatively $1.2 \mathrm{~g}$ twice a day and the child were vaccinated for the prevention of overwhelming post-operative infections: Pneumococcal, Meningococcal, and Haemophilus influenza vaccinations. The prophylaxis of thromboembolism was made with Clexane $20 \mathrm{mg}$ preoperatively and during hospitalization, twice a day. During the one year of follow-up the child had no postoperative complications.

\section{Case II}

A63-year-old lady with no significant pathological or family history was consulted in the ambulatory for profuse sweating, fatigue, weight loss, sensation of abdominal plenitude and echimotic purple. In the cytology of bone marrow aspiration sample, 45$75 \%$ of the cells were mononuclear lymphoid populations, with abundant cytoplasm and fringed cellular contours (hairy cells). The established diagnosis was that of hairy cell leukemia and splenomegaly. The surprise came from CT scan with contrast where the spleen of $35 \mathrm{~cm}$ length surpassed pubic symphysis. The patient was preoperatively prepared with red cell mass and plasma, reaching the values of laboratory tests that allowed surgery: platelets count $-72,000 / \mu \mathrm{g} / \mathrm{dl}$, hematocrit $-28.3 \%$, white blood cells count - 74,880/ $\mu$ l, INR (International Normalized Ratio) - 1.33 and PT (Prothrombin Time) - $14.2 \mathrm{sec}$. The patient was vaccinated against overwhelming sepsis: Pneumococcal, Meningococcal, and Haemophilus influenzae vaccinations.

\section{Surgical setting}

The patient was positioned on the surgical table for open surgery: in the dorsal decubitus, with the surgeon on the right and the assistant on the patient's left side.

\section{Surgical technique}

The abdomen was opened through a medial incision from the xifoid appendix up to $4 \mathrm{~cm}$ above the pubis. At the inspection of the abdomen, the spleen touched the uterus but had few adhesions. The lower pole of the spleen was mobilized (Figure 6) and after lysis of some adhesions, it was easy to reach the hilum vessels that were not too branched. The vessels were ligated and after the cutting of some adhesions on the posterior side of the upper lobe, the spleen, weighing $6300 \mathrm{~g}$, was removed from the abdomen (Figure 7). A subdiaphragmatic drain tube was fitted and the abdomen was closed. The operation lasted 140 minutes and $50 \mathrm{ml}$ of blood was lost.

\section{Postoperative evolution}

The patient resumed intestinal transit 3 days postoperatively. The thromboembolism prophylaxis was started preoperatively and continued during hospitalization with Clexane $20 \mathrm{mg}$ twice daily. Postoperatively Aspirin was prescribed. Antibiotic prophylaxis started preoperatively and continued for 3 days with Ceftazidime $1 \mathrm{~g}$ three times a day. The drainage tube was removed on day 4 and the patient was discharged on day 6 postoperatively. In the next 4 months, she was hospitalized once for a febrile, nonsurgical syndrome. Histopathological assessment showed diffuse infiltration of the venous sinuses of the red pulp by neoplastic cells and atrophic white pulp. Immunohistochemical exam found in the bone marrow biopsy diffuse lymphoid infiltration with small B-cell, expressing CD20, negative for Annexin A1; CD34 (stem cell marker) was positive in isolated cells $(\sim 1 \%)$.

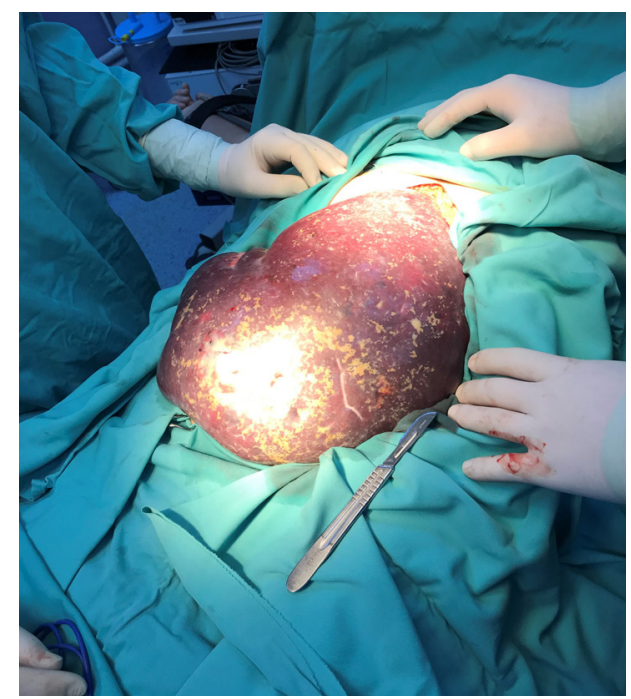

Figure 6: Mobilizing of the lower pole of the spleen.

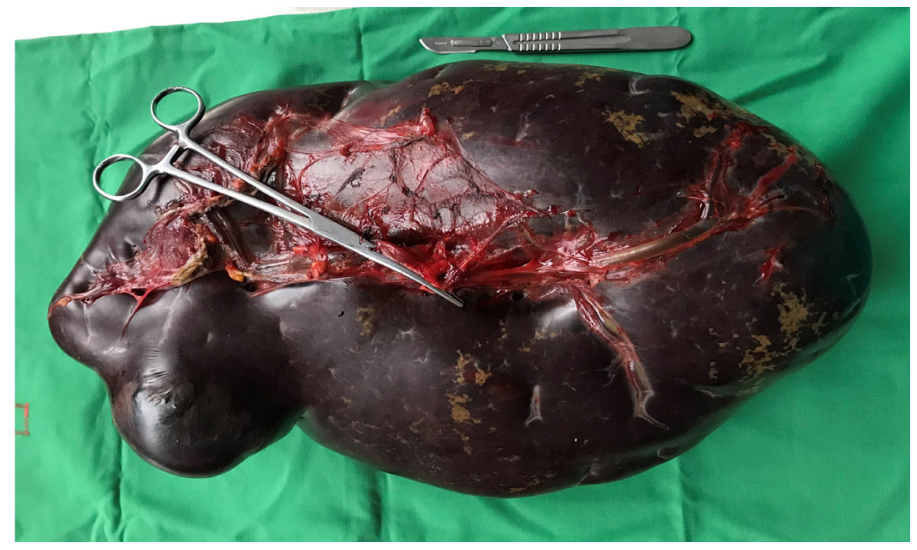

Figure 7: Spleen removed from the abdomen.

\section{Discussion}

Spleen preservation in blunt trauma, was first reported to the child by Upadhyaya and Simpson in 1968 [8] and is today the first option for spleen rupture in adults and children, grades I, II and III, according to the scale of the American Association for Surgery of Trauma (AAST), with 5 grades of splenic injury [9]. For grades IV and $\mathrm{V}$, non-operative management is associated with complications and higher failure rate [10]. The only steady condition mentioned in the literature in the choice of laparoscopic splenectomy for spleen lesions is that the patient should be hemodynamically stable $[1,3,4,6,11]$. On the other hand, asplenia increases the risk of serious infections and thromboembolic accidents and favors the progression of the atherosclerosis and the pulmonary hypertension [12] which has led surgeons from everywhere to try to preserve the spleen. In trauma, the criteria for partial splenectomy are the single 
pole lesion, without affecting the splenic pedicle, the patient to be hemodynamically stable and no lesions of other organs [13]. In the case of the child with spleen lesion operated laparoscopically by the Baia Mare team, there was the chance of temporarily stopping the bleeding and rapid taking of the therapeutic decision, before biological parameters deteriorated and filled the abdomen with blood. In the child, unlike the adult, the smooth muscle cells in the middle splenic artery layer have the ability to contract and reduce the lumen of the vessel, stimulated by noradrenaline and adenosine 5'-triphosphates released in the trauma [14], making a temporary haemostasis. The operative decision should be taken quickly, as long as the child is still hemodynamically stable. Children compensate well the blood loss; when tachycardia and hypotension occur, it means that $25-35 \%$ of the blood volume is lost and postoperative morbidity and mortality rates increase [15].

Unlike in planned splenectomy, where we legate the splenic artery on the upper edge of the pancreas at the beginning of the surgery, in this case, due to the blood infiltration of the spleen lodge, we approached the main vessels in the spleen hilum from the two poles. We always use the vascular sealing devices to cut the spleen pedicle by applying energy twice and cutting to the end. This technique is used even in the case of splenomegaly operated laparoscopically with blood vessels with diameters above $7 \mathrm{~mm}$, because after the ligation of the splenic artery, the blood flow is much reduced, especially if the short vessels of the gastrosplenic ligament are cut shortly afterwards. For the hilum vessels section there is the alternative to use vascular staplers [16,17], conventional ligatures [18] or hemoclips [19]. We preferred vascular sealing devices that can cut the vessels near the surface of the spleen, without damaging the pancreatic tissue, swollen, infiltrated with blood in this case. The vascular staplers and the endobag increase the cost of laparoscopic splenectomy.

Splenomegaly is present in $80-90 \%$ of patients with hairy cell leukemia [20], and splenectomy is indicated for splenomegaly and secondary symptomatic cytopenia [21] as in the case presented above. The most common classification of splenomegaly is that proposed by Hacket in 1944 [22] and places the enlarged spleen in 5 degrees:

- Grade 0: normal, not palpable spleen,

- Grade 1: palpable spleen only in deep inspiration,

- Grade 2: palpable spleen on the medioclavicular line, halfway between the navel and costal edge,

- Grade 3: the spleen expands close to the navel,

- Grade 4: the spleen goes past the navel,

- Grade 5: the spleen is near pubic symphysis.

In the case of the above presented patient, the spleen has surpassed pubic symphysis, a situation not known in the literature, for which the term of extreme splenomegaly would be appropriate. This term would differentiate it from massive splenomegaly that defines rank 5 on the Hackett scale.

Open splenectomy in the case of large spleens has the advantage of very good manual mobilization, with the excellent exposure of the vessels for which vascular sealing devices are very useful. In this case, due to spleen enlargement across the width of the abdomen, it was not possible to visualize and ligate the splenic artery at the upper edge of the pancreas. However, splenectomy was not difficult because there were few adherents, and the hilum vessels were slightly branched (Figure 7). In the case of open splenectomies, the ligation of hilum vessels with unresorbable thread is safer. After the removal of a large spleen, all patients are highly motivated postoperatively by the ease with which they mobilize and the absence of tension in the abdomen. Splenectomy is recommended as front-line therapy in patients with hairy cell leukemia and splines exceeding the $4 \mathrm{~cm}$ costal margin [23], as is the case of the patient from the County Hospital of Baia Mare. After a month, she received treatment with Cladribinum and is now in complete remission.

\section{Conclusion}

Laparoscopic splenomectomy for spleen lesions is feasible in children, with the condition to be hemodynamically stable. The decision of the operation must be taken quickly; when hypotension and tachycardia occur, it is too late for good postoperative results. Splenomegaly can reach extreme limits in hematological diseases. The abundance of peritoneal adhesions and the branching of the vessels in the spleen hilum make the difference between easy and difficult splenectomy.

\section{Ethics approval and consent to participate}

The study was approved by the institutional board of ethics (Ethics Committee of Emergency County Hospital of Baia Mare). Consent to participate was not required, because photos and CT images was anonymized and cannot be traced back to the patients.

\section{References}

1. Agresta F, Ansaloni L, Baiocchi GL, et al. Laparoscopic approach to acute abdomen from the Consensus Development Conference of the Società Italiana di Chirurgia Endoscopica e nuove tecnologie (SICE), Associazione Chirurghi Ospedalieri Italiani (ACOI), Società Italiana di Chirurgia (SIC), Società Italiana di Chirurgia d'Urgenza e del Trauma (SICUT), Società Italiana di Chirurgia nell'Ospedalità Privata (SICOP), and the European Association for Endoscopic Surgery (EAES). Surg Endosc. 2012; 26: 2134-2164.

2. Targarona EM, Balagué C, Trias M, Is the laparoscopic approach reasonable in cases of splenomegaly?. Semin Laparosc Surg. 2004; 11: 185-1190.

3. Ermolov AS, Tlibekova MA, Yartsev PA, et al. Laparoscopic Splenectomy in Patients with Spleen Injuries. Surg Laparosc Endosc Percutan Tech. 2015; 25: 483-486.

4. Habermalz B, Sauerland S, Decker G, et al. Laparoscopic splenectomy: the clinical practice guidelines of the European Association for Endoscopic Surgery (EAES). Surg Endosc. 2008; 22: 821-848.

5. Heniford BT, Park A, Walsh RM, et al. Laparoscopic splenectomy in patients with normal-sized spleens versus splenomegaly: does size matter?. Am Surg. 2001; 67: 854857. 
6. Habermalz B, Sauerland S, Decker G, et al. Laparoscopic splenectomy: the clinical practice guidelines of the European Association for Endoscopic Surgery (EAES), Surg Endosc. 2008; 22: 821-848.

7. https://www.youtube.com/watch?v=KBDyf1u-_Tk\&amp$; \mathrm{t}=6 \mathrm{~s}$

8. Upadhyaya P, Simpson JS. Splenic trauma in children, Surg Gynecol Obstet. 1968; 126: 781-790.

9. Prokop M GM. Spleen. In Verlag. GT (ed) Computed tomography; spiral and multilayer. Edition Germany: 2003; 514.

10. Di Saverio S, Moore EE, Tugnoli G, et al. Non operative management of liver and spleen traumatic injuries: a giant with clay feet. World J Emerg Surg. 2012; 7: 3.

11. Huang GS, Chance EA, Hileman BM, et al. Laparoscopic Splenectomy in Hemodynamically Stable Blunt Trauma. JSLS. 2017; 21: e2017.00013.

12. Robinette CD, Fraumeni JF. Jr Splenectomy and subsequent mortality in veterans of the 1939-45 war. Lancet. 1977; 2: 127- 129.

13. Li H, Wei Y, Peng B, et al. Feasibility and safety of emergency laparoscopic partial splenectomy: A retrospective analysis. Medicine (Baltimore). 2017; 96: e6450.

14. Ortiz PP1, Díaz P, Daniel-Lamazière JM, et al. Morphometry of the human splenic artery: muscular columns, morphofunctional aspects and developmental implications, Histol Histopathol. 1998; 13: 315-324.
15. Schwaitzberg SD, Bergman KS, Harris BH. A pediatric trauma model of continuous hemorrhage. J Pediatr Surg. 1988; 23: 605-609.

16. Vargün R, Göllü G, Fitöz S, et al. En-bloc stapling of the splenic hilum in laparoscopic splenectomy. Minim Invasive Ther Allied Technol. 2007; 16: 360-362.

17. Vecchio R, Marchese S, Swehli E, et al. Splenic hilum management during laparoscopic splenectomy. J Laparoendosc Adv Surg Tech A. 2011; 21: 717-720.

18. Dalvi AN, Thapar PM, Deshpande AA, et al. Laparoscopic splenectomy using conventional instruments. J Minim Access Surg. 2005; 1: 63-69.

19. Machado MA, Makdissi FF, Herman P, et al. Exposure of splenic hilum increases safety of laparoscopic splenectomy. Surg Laparosc Endosc Percutan Tech. 2004; 14: 23-25.

20. Venkatesan S, Purohit A, Aggarwal M, et al. Unusual presentation of hairy cell leukemia: a case series of four clinically unsuspected cases. Indian J Hematol Blood Transfus. 2014; 30: 413-417.

21. Van Norman AS, Nagorney DM, Martin JK, et al. Splenectomy for hairy cell leukemia. A clinical review of 63 patients. Cancer. 1986; 57: 644-648.

22. Hackett LW. Spleen measurement in malaria. J Nat Malar Soc. 1944; 3: 121-133.

23. Jansen J, Hermans J. Splenectomy in hairy cell leukemia: a retrospective multicenter analysis. Cancer. 1981; 47: 20662076. 